\title{
Regime Concorrencial e Contabilização de Perdas: Possíveis Consequências
}

\begin{abstract}
Ronaldo dos Santos Alves Rodrigues
Doutorado em andamento em Contabilidade pela Universidade Federal do Paraná -

UFPR

Professor na Universidade do Contestado - UnC Avenida Sete de Setembro, 4995 Jazz, Sala 06. Água Verde. Curitiba/PR. CEP: 80250-

205

E-mail: ronaldo.sarodrigues@gmail.com

Ademir Clemente

Pós-doutorado em Lógica Fuzzy Aplicada - COPPE/Universidade Federal do Rio de Janeiro

Professor da Universidade Federal do Paraná- UFPR Av. Prefeito Lothário Meissner, 632. Jardim Botânico. Curitiba/PR. CEP: 80210-170 E-mail: ademir@ufpr.br

Alceu Souza

Doutorado em Administração de Empresas pela Fundação Getúlio Vargas - FGV/SP Professor na Pontifícia Universidade Católica do Paraná - PUC/PR. Rua 24 de Maio 980. Curitiba/PR. CEP: 80230-080 E-mail: alceu.souza@pucpr.br
\end{abstract}

\section{RESUMO}

Embora haja consenso de que o preço é uma variável mercadológica e de que é condicionado pela concorrência, o resultado operacional sempre depende da eficiência do processo produtivo, dos custos de produção. Incluir indevidamente no custo do produto valores de perdas implica não reconhecer eventuais não conformidades de produção ou de logística. Essa contabilização incorreta decorre de uma concepção errônea da gestão de custos segundo a qual não há nada a fazer uma vez que os gastos já foram realizados e pode estar associada à prática generalizada de precificar via Mark-up. Este artigo é um ensaio teórico objetivando analisar as implicações financeiras e gerenciais da contabilização incorreta das perdas decorrentes de não conformidades do processo produtivo. Do ponto de vista financeiro, a contabilização inadequada das perdas e a tentativa de recuperação repassando-a ao Mark-up compromete a competitividade da empresa e a sua sustentabilidade. Do ponto de vista gerencial, essa prática esconde deficiências de gestão e dificulta ações corretivas.

Palavras-chave: Contabilização de perdas. Perdas normais e anormais. Gestão de custos. Informação contábil. 


\section{Competition and Loss Accounting: Possible Consequences}

\section{ABSTRACT}

Although there is a consensus for the price as a market variable and that it is conditioned by competition the operating result always depends on the efficiency of the production process and the production costs. Improperly included in the cost of the product values are the losses for not recognizing nonconformities of production or logistics. This incorrect accounting results are due to an erroneous conception of cost management according to which there is nothing one can do for avoiding expenditures that have already taken place and may be associated with the widespread practice of pricing via Mark-up. This article is a theoretical essay aimed to analyse the financial and managerial implications of incorrect accounting for nonconformities of the production process. From the financial point of view, the inadequate accounting of losses and the attempt to recover them by passing it on to Mark-up compromises the company's competitiveness and sustainability. From the managerial point of view, this practice hides management deficiencies and hinders the course for corrective actions.

Keywords: Losses Accounting. Normal and abnormal losses. Costs management. Accounting information.

\section{Régimen de Competencia y Contabilidad de Pérdidas: Posibles Consecuencias}

\section{RESUMEN}

Si bien existe consenso en que el precio es una variable de mercado y que está condicionado por la competencia, el resultado operativo siempre depende de la eficiencia del proceso productivo, de los costos de producción. Incluir pérdidas en el costo del producto de manera indebida implica no reconocer eventuales no conformidades de producción o logística. Esta contabilidad incorrecta se debe a una idea errónea de la gestión de costos de que no hay nada que hacer una vez que los gastos ya se han incurrido y puede estar asociado con la práctica generalizada de fijar precios a través del margen. Este artículo es un ensayo teórico que tiene como objetivo analizar las implicaciones financieras y de gestión de la contabilización incorrecta de las pérdidas derivadas de no conformidades en el proceso productivo. Desde el punto de vista financiero, la inadecuada contabilización de las pérdidas y el intento de recuperación traspasándolas al Mark-up compromete la competitividad de la empresa y su sostenibilidad. Desde el punto de vista gerencial, esta práctica esconde deficiencias gerenciales y dificulta las acciones correctivas.

Palavras Clave: Contabilidad de pérdidas. Pérdidas normales y anormales. Gestión de costes. Información de cuenta. 


\section{INTRODUÇÃO}

O conceito econômico de empresa como locus de acumulação do capital exige a seleção de ações orientadas estrategicamente para a sua sobrevivência e seu crescimento. Em síntese, as estratégias devem ser avaliadas pelo seu potencial para gerar lucro no médio e longo prazo. (Souza \& Clemente, 2011). Diante disso, os gestores devem ter estimativas robustas de preços, custos e probabilidade de cenários para delinearem correção de rumos às estratégias já selecionadas. Em particular, a informação contábil adequada possibilita o desenvolvimento, avaliação e a implementação de estratégias gerenciais (Shank et al., 1997, p. 115 apud Souza \& Clemente, 2011). Assim a contabilidade deve possuir a capacidade de fornecer informações de qualidade e tempestivas para tomada de decisão (ludícubus, Martins, \& Carvalho, 2005). A relevância informacional ocorre na medida em que as informações são úteis na formulação de estratégias objetivando vantagem competitiva sobre os concorrentes (Day, 1999; Souza \& Clemente, 2011).

A informação de custos é indispensável à precificação de bens e serviços (Amaral \& Guerreiro, 2018). A possibilidade da redução de custos pode representar uma vantagem competitiva em relação aos concorrentes (Possas, 2006). Shank e Govindarajan (apud Souza \& Clemente, 2011) apontam que os custos devem ser utilizados para o desenvolvimento de estratégias coerentes com 0 ambiente de competição. Em mercados competitivos, as empresas precisam ter como referência os preços praticados no mercado e os requisitos de qualidade esperados para desenvolver a gestão estratégica de custos (Souza \& Clemente, 2011). Assim, a informação sobre custos é indispensável ao processo de formulação e avaliação de estratégias, pois existe uma relação de interdependência entre estratégia, decisões de investimentos e estrutura de custos (Souza \& Clemente, 2011).

Para que as empresas possam continuar competitivas no mercado precisam ajustar suas estratégias e desenvolver métodos para transferência de valor aos seus consumidores que procuram produtos e serviços com maior qualidade a preços baixos 
(Goulart \& Rosa, 2004). Assim, conhecer os custos auxilia no processo de tomada de decisão (Johnson \& Kaplan, 1993) e quanto maior o nível de detalhamento da informação, mais embasada será a tomada de decisão (Bianchet, Zanin, Camargo, \& Diehl, 2016).

No cenário atual, marcado pela competitividade, a tomada de decisão inicia-se pela observação das tendências de variáveis macroeconômicas e de seus efeitos no processo de competição no setor em que a firma está inserida. Assim, conforme a percepção da estrutura de mercado, a firma contará com maior ou menor liberdade para a tomada de decisão e precificação dos produtos. Todavia, para que as decisões tomadas melhorem seu ranking de acertos, a contabilização dos custos deve ser realizada de forma rigorosa e em observação aos princípios e normas contábeis.

Segundo Martins (2010), integram o custo todos os gastos relativos a bens e serviços utilizados na produção de outro bem ou serviço e, em particular, é necessário que as perdas normais decorrentes do processo produtivo e as perdas anormais que são involuntárias sejam corretamente identificadas e contabilizadas. Quando o custo do produto incorpora indevidamente valores de perdas, têm-se informações contábeis distorcidas, que não representam a realidade dos custos e tampouco a situação real da empresa e que podem levar a decisões completamente inadequadas (Goulart \& Rosa, 2004). Apesar disso, é comum a prática de "diluir" o valor de perdas no custo dos produtos e serviços. Essa prática decorre de uma concepção errônea da gestão de custos segundo a qual não há nada a fazer uma vez que os gastos já tenham sido realizados. Isso é prejudicial internamente porque, na falta de um "feedback" adequado, as mudanças necessárias deixam de ser efetivadas e, do ponto de vista externo, apresenta risco elevado e desnecessário de perda de posição competitiva no mercado.

O objetivo deste artigo é, a partir de revisitação de conceitos, apresentar um ensaio teórico em que se busca analisar as implicações da contabilização incorreta de perdas e da necessidade de um novo olhar sobre a gestão de custos, posicionando-a como parte da gestão estratégica e, dessa forma, juntamente com a contabilização correta dos custos, das análises do contexto econômico e da estrutura concorrencial 
fixar preços que melhorem a agregação de valor. Tal temática possui relevância visto ser comum a prática da diluição das perdas no custo do produto, como também o reconhecimento de que as pesquisas que versam sobre 0 assunto possuírem cunho empírico.

Além dessa introdução, este artigo contém uma revisão bibliográfica, discussão das consequências financeiras e das consequências gerenciais da contabilização inadequada, exemplos e conclusão.

\section{CONTEXTUALIZAÇÃO E RELEVÂNCIA}

Nas primeiras décadas da revolução industrial, a produção dava-se de forma artesanal, o mercado encontrava-se inexplorado e em franca expansão, a produção industrial era intensiva de mão de obra, predominando a manufatura com baixo nível de padronização. Porém, logo se tornaram evidentes as vantagens da divisão do trabalho e do funcionamento da "mão invisível", que garante o equilíbrio de mercado pela livre interação entre seus players, como o economista inglês Adam Smith já defendia em 1776 (Smith, 1996).

Nas três primeiras décadas do Século XIX, predominou a Lei de Say, devida ao economista francês Jean Baptiste Say, segundo a qual "toda oferta gera a sua própria demanda", cuja maior implicação foi orientar a gestão para a eficiência dos processos produtivos na busca de maior produção, sem considerar que a demanda poderia tornarse uma restrição para o aumento de riqueza. Tanto Say quanto Smith receberam contribuições e, já no início do Século XX, a mão invisível de Adam Smith começa a ser substituída pela "mão visível" dos gestores (Chandler, 1977).

A padronização da produção é eleita por Taylor (1989) e por Henry Ford (Minha Filosofia e Indústria, 1914) como base para os sistemas de produção em massa. Ao declarar, em 1909, que seus clientes poderiam escolher qualquer cor para o Ford $T$ desde que fosse preto, Ford proclamava a produção de grandes lotes padronizados para melhorar a produtividade e, por consequência, também diluir os custos, 
principalmente os custos fixos.

A crise de 1929 colocou em xeque a Ley de Say e a economia americana se defrontou com a realidade de dispor capacidade produtiva (sinônimo de geração de riqueza), mas não conseguir vender a produção. É nesse contexto, com a consciência de que a produção precisa ter, senão a garantia, pelo menos a expectativa de que seja vendida para efetivar a criação de riqueza, que a mão visível dos gestores, inclusive governos, deve garantir o funcionamento da economia. Essa estratégia é vista no "New Deal", um conjunto de políticas públicas intervencionistas do presidente Franklin Delano Roosevelt, e na clássica Teoria Geral do Emprego do Juro e da Moeda, do economista inglês John Maynard Keynes, de 1936.

O boom que emergiu após a Segunda Guerra Mundial se estendeu praticamente até 1970. Nesse período novamente a produção não encontra dificuldade para ser colocada no mercado, fazendo lembrar a Lei de Say. Apesar da contribuição de Jonathan N. Harris ao propor em 1936 o Custeio Direto, que elege a venda como geradora de riqueza e do Método das Unidades de Esforço de Produção (La Méthod GP) proposto pelo francês George Perrin nos anos 40, a estratégia de produção em massa, mesmo tendo padecido o revés dos anos 30 , ainda direcionou o comportamento gerencial.

Somente a partir dos anos 70 , com a produção flexível, baseada em pequenos lotes e propiciando custos iguais ou menores devido a mudanças tecnológicas, as vendas passam a direcionar a produção. O marketing constitui a ferramenta para atender às necessidades voláteis dos consumidores procurando otimizar a utilização da capacidade produtiva. As estratégias de posicionamento e de diferenciação ampliaram a gama de produtos ofertados e a contabilidade se defrontou com uma nova realidade: aumento dos custos fixos e dificuldades adicionais para dimensionar os custos variáveis unitários. Atualmente o mercado é o campo de ação das vantagens dos agentes econômicos e se apresenta competitivo, com produtos de baixo preço, boa qualidade e com frequentes modificações (Possas, 2006; Bornia, 2010).

As empresas buscam continuamente melhoria de processo produtivo resultando 
naturalmente em diferenciação; aumento de produtividade e redução de custos, o que permite melhorar a sua competitividade.

É nesse contexto que a contabilização inadequada de perdas implica visão distorcida dos custos unitários e de margens na arena atual de competição. O que se argumenta, neste artigo, é que a contabilização correta dos custos incluindo informações detalhadas sobre as parcelas de custos efetivos, refugos, desperdícios, perdas etc. e, ainda, a separação dos custos em fixos e variáveis não é um preciosismo contábil, mas sim uma necessidade para o desenho de estratégias competitivas. Devido às inúmeras variáveis envolvidas, a fixação de preço nos dias atuais não pode prescindir do controle efetivo das atividades produtivas.

É nesse contexto marcado pela competitividade, que o número de empresas que atuam no mesmo setor, o tamanho da empresa e a diferenciação dos produtos reduzem a capacidade de precificação (Banterle, Carraresi, \& Cavaliere, 2011). Amaral e Guerreiro (2018) apontam que os estudos sobre fixação de preços sugerem que devem ser definidos com base nos custos ou nas ofertas da concorrência. Uma estratégia para o estabelecimento dos preços, em mercados competitivos é fixar os preços iguais aos dos competidores ou uma cotação abaixo do preço da competição. Outra opção depende da existência de um grande volume de vendas, com margens menores, para que a alternativa seja mais rentável (Cogan, 2013). Outros autores apontam que para a precificação deve considerar os fatores externos, preços e custos dos concorrentes (Kotler, 1999; Nagle \& Holden, 2003; Costa, Ferreira, \& Saraiva Junior; 2013). Em síntese, na arena atual as firmas atuam para atender a uma demanda volátil e seu comportamento em termos de estratégia de posicionamento, incluindo o preço, deve considerar a estrutura competitiva do mercado em que estão inseridas. A Figura 1 apresenta um resumo das possibilidades quanto à concorrência. 


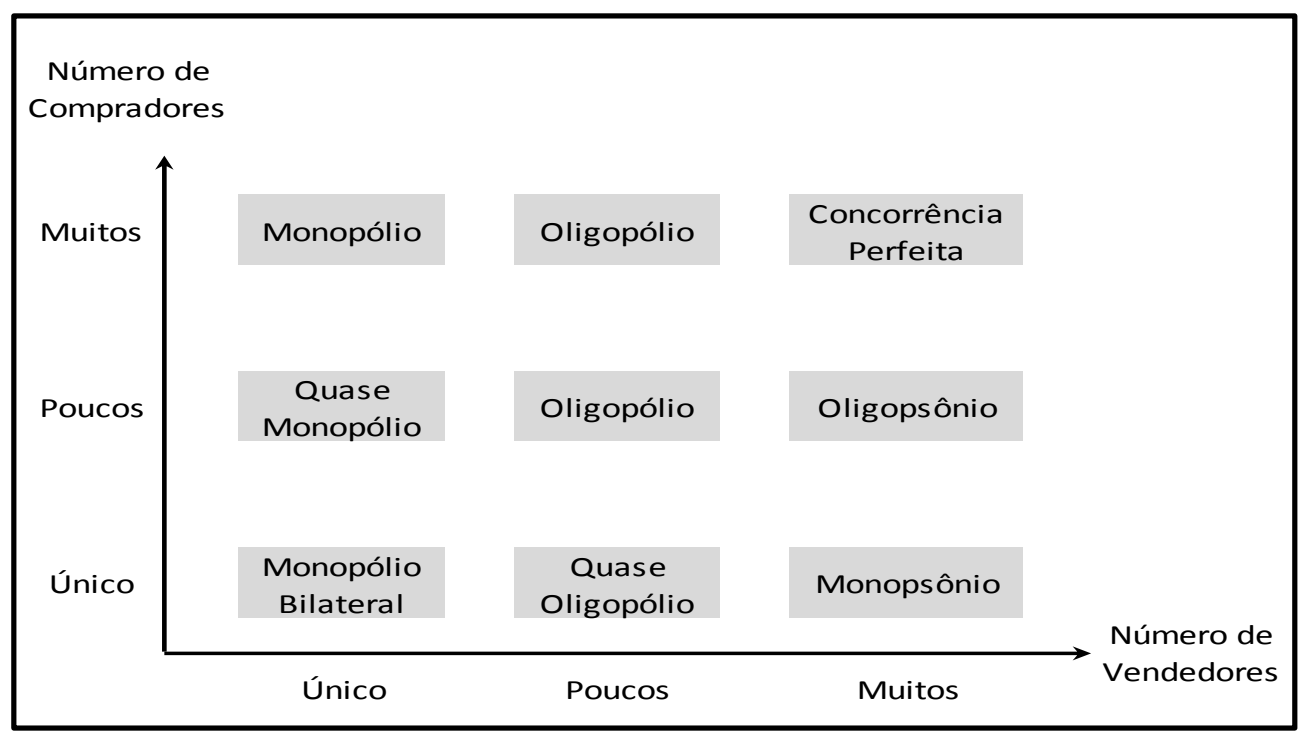

Figura 1: Estruturas de Mercado

Fonte: Stackelberg (1952).

Segundo Costa et al. (2013) a estrutura de mercado representa o elemento mais importante para a fixação do preço de um produto pois, dependendo da estrutura, a empresa terá maior ou menor espaço para fixar seus preços. É no contexto competitivo que a empresa precisa gerir seus custos para que a fixação do preço não the seja arriscada e desfavorável.

No Quadro 1, as abordagens para fixação de preço são classificadas como tradicional e contemporânea para melhor entendimento.

\begin{tabular}{|l|l|l|}
\hline & Resultados do Processo & Abordagem \\
\hline$a$ & Produtos Acabados e Comercializáveis & Contemporânea $\rightarrow$ Custo do Produto (a) \\
\hline$b$ & Produtos Acabados e Não-comercializáveis & \\
$c$ & Sobras de Material & \\
$d$ & Refugos & Tradicional $\rightarrow$ Custo do Produto $(a+b+c+\ldots+g+h)$ \\
$e$ & Retrabalhos & \\
$f$ & Ociosidade & \\
$g$ & Ineficiência & \\
$h$ & Perdas inesperadas & \\
\hline
\end{tabular}

\section{Quadro 1: Abordagem contemporânea e tradicional}

Fonte: Autores (2019).

$\mathrm{Na}$ abordagem aqui denominada tradicional, o custo e o preço do produto são 
entendidos como o resultado do somatório das etapas necessárias para a sua elaboração. $\mathrm{Na}$ abordagem contemporânea o custo do produto é entendido como o resultado do processo somente dos produtos acabados e comercializáveis, não incorporando outros itens.

As empresas podem adotar em relação ao mercado a postura tradicional ou a postura contemporânea, como mostra a Figura 2.

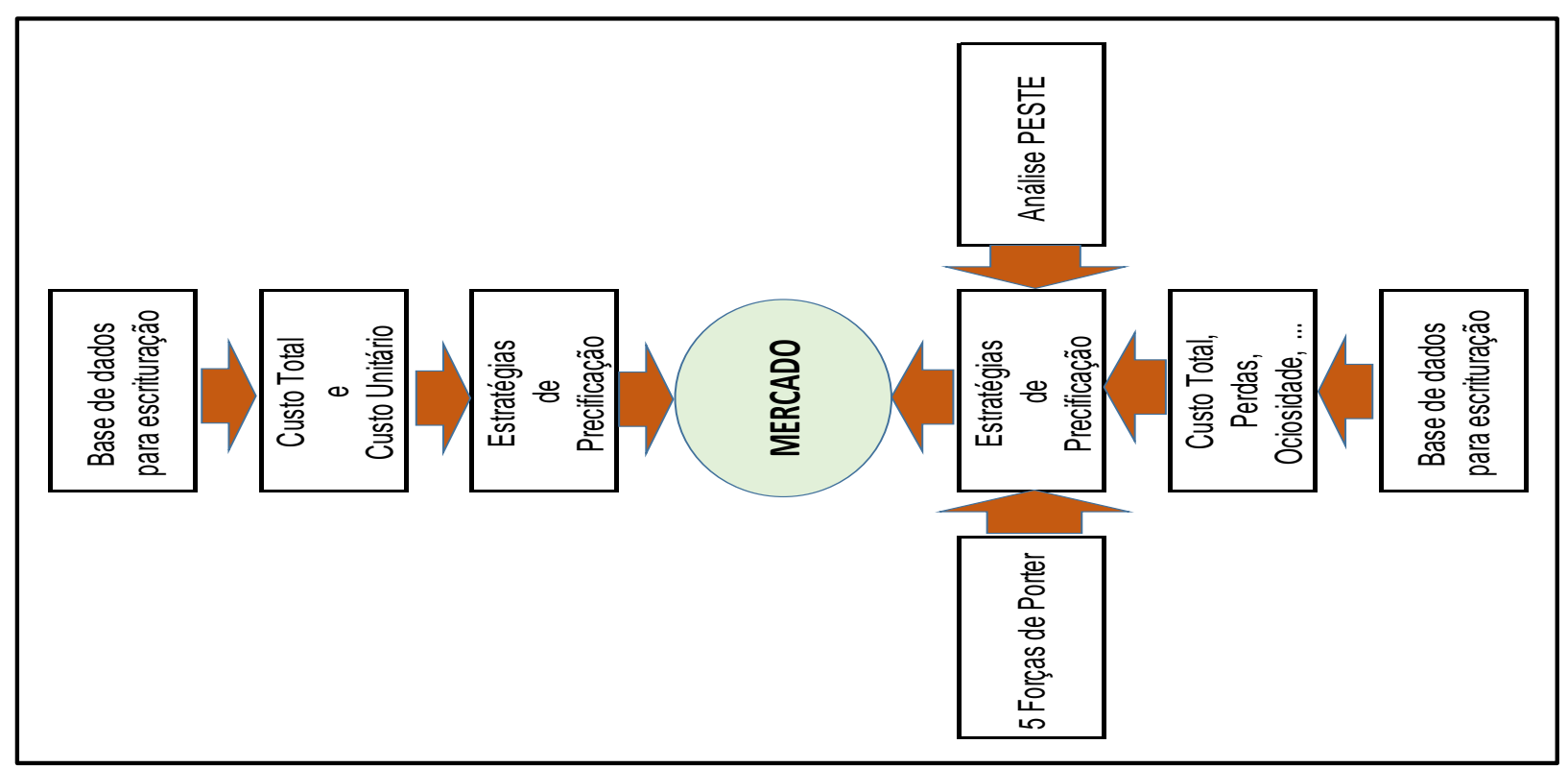

Figura 2: Relevância da informação de custos nas Posturas Tradicional e Contemporânea Fonte: Autores (2019).

Quando a empresa adota a postura tradicional considera que o mercado absorverá sua produção aos preços que ela estabelecer e, por isso, precificará de acordo com os seus custos e suas despesas. Ao contrário, quando a empresa adota a postura estratégica tem o mercado como ponto de partida, avalia as preferências e a disposição para pagar por produtos e serviços com diferentes características e, então, considerando o ambiente em que atua, tomará decisões sobre os preços a praticar. $O$ número de participantes, o grau de concentração, as possibilidades de diferenciação dos produtos, as barreiras à entrada e as estruturas de custos, são características e dimensões das estruturas de mercado (Possas, 2006). Em síntese, conforme a 
estrutura de mercado em que a empresa esteja inserida, terá maior ou menor liberdade para fixação de preços a partir dos custos dos produtos, o que realça a relevância da contabilização correta dos custos, condição necessária para a melhoria de processos e permanência no mercado.

\section{REVISITANDO CONCEITOS DE CUSTOS}

Segundo Martins (2010), do ponto de vista contábil, custo pode ser definido como a expressão monetária dos recursos utilizados no processo de produção de um bem ou serviço. A despeito da clareza do conceito (definição constitutiva), o processo de estimativa do custo (definição operacional) requer discussões aprofundadas. Questões aparentemente simples podem apresentar grande dificuldade de operacionalização, por exemplo:
a) Paradas inesperadas de máquinas e equipamentos representam dispêndio, mas não recebem a contrapartida em volume de produção;
b) Sobras inaproveitáveis de matérias primas obviamente significam desembolso, porém não têm valor comercial;
c) Refugos que consomem material e custos indiretos e não resultam em produtos comercializáveis;
d) Retrabalho com material reaproveitado, mas com pagamento em dobro da mão de obra utilizada;
e) Ineficiência de processo, quando todos os recursos disponibilizados em certo período de tempo foram utilizados, mas o volume de produção ficou aquém do esperado;
f) Ociosidade dos recursos disponibilizados, mas não utilizados em sua plenitude etc.

Qualquer que seja o caso, as boas práticas de gestão recomendam a rigorosa investigação da origem dos problemas: Má qualidade de material; mão de obra sem o devido treinamento; máquinas e equipamentos com baixa produtividade decorrente de estratégias de manutenção inadequadas; combinação dos fatores citados resultando em produtos aquém da qualidade esperada. Todos esses eventos estão na origem de eventuais não conformidades do processo. Essas não conformidades não estão 
claramente resolvidas nos Métodos de Custeio mais tradicionais: Custeio por Absorção e variantes; Custeio Direto; Custeio por Atividades e Unidades de Esforço de Produção. Ressalta-se que o Custo Padrão não é propriamente um método de custeio, apenas uma forma de registro (histórico, corrigido ou padrão), mas que pode estar presente em cada um dos métodos de custeio e, assim, facilitar sobremaneira a mensuração das não conformidades do processo.

Maher (2001, p. 64) define custo como um sacrifício de recursos, não devendo ser confundido com despesa. Esse sacrifício ocorre independentemente de ser contabilizado como ativo ou como despesa, pois, "se o custo for contabilizado como um ativo (aluguel de um escritório pago antecipadamente, por exemplo), ele se torna despesa quando o ativo for consumido (o escritório for utilizado durante certo tempo, após o aluguel ter sido pago". Horngren, Datar e Foster (2004) entendem custo como recurso sacrificado ou renunciado para conseguir um objetivo específico. Nesse entendimento "um custo é normalmente medido como quantia monetária que precisa ser paga para adquirir bens ou serviços" (Hornegren, Datar, \& Foster, 2004, p. 26). Em uma perspectiva um pouco mais ampla, Martins (2010) define custo como "gasto relativo a um bem ou serviço utilizado na produção de outros bens e serviços".

Souza e Clemente (2011) apresentam dois conceitos de custo: um operacional, similar ao de Martins (2011) e outro estratégico que apresenta custo como consequência de decisões de investimentos decorrentes da estratégia competitiva selecionada. Esses autores também mostram que no processo de transformação de matérias-primas, em produtos acabados, podem ser adotados certos níveis de agregação: custo primário, custo de transformação, custo de produção, custo dos produtos fabricados, custos dos produtos vendidos, custos mercadológicos e custos pela ótica da economia. Essa nomenclatura é importante para o monitoramento do processo produtivo e comparação entre produtos acerca do consumo de recursos.

Quanto às normas legais, o CPC 16 (2011) se refere a custos de transformação como somente aqueles gastos diretamente relacionados com as unidades produzidas ou com as linhas de produção e ainda aqueles indiretos de produção. De uma 
perspectiva normativa, Santos, Schmidt, Pinheiro e Nunes (2015) definem custo como sendo "o consumo de ativos necessários para a produção do produto ou para colocação da mercadoria à disposição dos clientes no estabelecimento comercial, de forma que a empresa alcance os seus fins específicos, expressos em termos monetários, ou para a prestação de serviços ao cliente". Já o artigo 290 do Regulamento do Imposto de Renda (1999) e o artigo 13 da Lei o 1.598 (1977) estabelecem que o custo de produção de bens ou serviços vendidos compreende, obrigatoriamente: custo de aquisição de matérias-primas, custo de pessoal, custos de locação, encargos de amortização e encargos de exaustão. Salienta-se que os custos referidos acima devem estar relacionados com a produção. Em uma abordagem mais gerencial, Cooper e Kaplan (1988), Johnson e Kaplan (1993) afirmam que os relatórios financeiros são elaborados a partir das informações fornecidas pelos sistemas de custos. Tais sistemas possuem a função de distribuir custos nos demonstrativos financeiros, facilitar o controle de processos, computar custos dos produtos e auxiliar em estudos especiais.

Em síntese, dentre os autores revisitados, há consenso quanto a dois componentes do conceito de custo: uso de recursos (materiais, humanos, tecnológicos, etc.) e intencionalidade de uso. Assim, ocorre custo quando certo recurso é utilizado no processo produtivo com vistas a obtenção de receita. Essas utilizações de recursos, algumas vezes, são obtidas por estimativa, procurando-se, no entanto, a maior precisão possível.

\subsection{Perdas}

Perdas não devem ser confundidas com despesa e tampouco com custo (Souza \& Clemente, 2011; Martins, 2003; Biachet et al., 2016; Goulart \& Rosa, 2004). Martins (2003) declara que as perdas possuem características de anormalidade e involuntariedade não representando um sacrifício feito com a intenção de obter receita. As perdas também podem se referir a unidades de produção recusadas, que são jogadas fora, ou seja, unidades parcial ou integramente acabadas que podem estar 
com defeito (Horngren, Foster, \& Datar, 2004). Já Maher (2001, p.206) entende perdas na produção como "produtos danificados, que não atendem às especificações ou que não podem ser processados adicionalmente ou vendidos aos clientes como um produto bom". Bornia (2010) aponta que na literatura contábil a perda é normalmente vista como o valor dos insumos consumidos de forma anormal. Para esse autor, as perdas são tratadas como desperdícios.

Do ponto de vista gerencial, para Shingo (1996), todas as atividades que não agregam valor, como caminhar para obter as peças, desembalar peças vindas de fornecedores, esperar, entre outras, representam perda e ele as classifica em sete tipos: superprodução; transporte; processamento; fabricação de produtos defeituosos; movimento; espera e estoque. Para esse autor, as atividades que agregam valor constituem o processamento enquanto as que não agregam valor, ou seja, as perdas devem ser eliminadas ou mitigadas por meio de constante melhoria no processo de trabalho. Nessa mesma vertente, Bornia (1995) afirma que as perdas diminuem o valor dos produtos e que a empresa deve se concentrar em eliminá-las.

Estrela, Cruz e Severiano Filho (1999) afirmam que as perdas devem ser eliminadas e que também é necessário minimizar o trabalho adicional para maximizar o resultado do trabalho efetivo. Afirmam também que para eliminar as perdas é preciso antes identificar suas causas. Dessa forma, a identificação e quantificação das perdas deve integrar a análise do processo de produção e é indispensável enquanto ferramenta de apoio gerencial. Para Lopes, De Brum e Grefori (2008), é papel essencial da gerência detectar e eliminar as perdas que ocorrem em suas atividades para que a empresa se mantenha competitiva. É essa detecção que auxilia na descoberta das causas dos desperdícios e possibilita propor soluções, assim como trabalhar para melhoria contínua dos produtos e serviços.

Do ponto de vista normativo, de acordo com o CPC 16 (2011) as perdas são reconhecidas como despesa do período, bem como valores anormais de desperdício de materiais, mão de obra ou outros insumos de produção.

O conhecimento de eventuais perdas na produção possibilita aos 
administradores tomar decisões sobre o aperfeiçoamento da qualidade e redução dos custos (Maher, 2001) e, isso é corroborado por Horngren, Foster, \& Datar (2004); Martins (2003); Bornia (2010); Bhargava (2018) para os quais a melhoria contínua do processo requer distinguir dois tipos de perdas: as perdas normais, que são inerentes ao processo de produção, e as perdas anormais, que não decorrem da produção.

\subsection{Perdas Normais}

Para Martins (2003), perdas normais "são inerentes ao próprio processo de produção; são previsíveis e já fazem parte da expectativa da empresa, constituindo-se num sacrifício que ela sabe que precisa suportar para obter o produto". Quando ocorrem perdas normais no processo produtivo, essas são corretamente consideradas como custo do produto (Maher, 2001; Martins, 2003). De forma análoga, Horngren, Datar e Foster (2004); Maher (2001) definem as perdas normais como inerentes ao processo de produção, que ocorrem mesmo em condições eficientes de produção, isto é, as perdas normais são esperadas como parte do processo de produção e devem integrar o custo dos bens e serviços produzidos.

É importante notar que os conceitos apresentados pelos autores supracitados diferem do conceito de não conformidade de processo apresentado por Taguchy (1988), ou seja, que toda não conformidade de processo gera custos e que será paga agora ou no futuro por alguns dos players da cadeia de valor. Por exemplo, caso se utilize de $10.000 \mathrm{~kg}$ de material, dos quais são aproveitados apenas $9.300 \mathrm{~kg} \mathrm{em}$ condições normais, para os produtos será apropriado o valor correspondente aos $10.000 \mathrm{~kg}$. Logo, o custo do material perdido fará parte do custo dos produtos fabricados (Martins, 2003; Bianchet et al., 2016). Da mesma forma, se num processo de produção houver incidência rotineira de $0,5 \%$ de peças produzidas com defeito, o custo incorrido deverá corretamente ser apropriado às peças com conformidade, que representam 99,5\% das peças produzidas. Em qualquer dos casos o custo será pago pelo consumidor que em um momento futuro buscará este produto em outros fornecedores que não tenham essa distorção de valor. 
Quanto à contabilização, para Martins (2010) as perdas normais durante o processo produtivo devem integrar o custo do produto em elaboração (Resultado) e o estoque de produtos em elaboração (Ativo Circulante). Em assim procedendo se estará incluindo no custo do produto as perdas normais do processo produtivo. Essas perdas devem ter sido previstas no plano de produção.

\subsection{Perdas Anormais}

Para Martins (2010) as perdas anormais ocorrem de forma involuntária "e não representam sacrifício premeditado, como é o caso de danificações extraordinárias de materiais por obsoletismo, degeneração, incêndio, desabamento etc.". As características principais são a aleatoriedade e a involuntariedade com que ocorrem os eventos de perdas anormais. De forma similar Horngren, Datar e Foster (2004) argumentam que as perdas anormais não ocorreriam em condições operacionais eficientes. Nessa linha de raciocínio, Maher (2001) aponta que as perdas anormais são devidas a razões não usuais ou anormais, e que se consideram os seus valores como despesas do período. Em vertente mais ampla, Goulart e Rosa (2004) asseguram que a não conformidade de mão de obra, de maquinário e de matéria-prima também configuram perdas anormais, assim como devolução de produtos, que se reflete em perda econômica e financeira e afeta a reputação da empresa. Aqui se observa um conflito de conceitos porquanto é subjetivo afirmar que ineficiência de mão de obra, maquinário e qualidade de matéria-prima sejam eventos inesperados e não controláveis. Corroborando o conflito, Bhargava (2018) afirma que a perda anormal é causada por condições inesperadas ou anormais e que esses valores devem ser segregados do custo, podendo-se citar como exemplo os acidentes, as quebras de máquinas, etc.

A literatura pesquisada destaca três características da perda anormal: não rotineira, involuntária e aleatória (Maher, 2001; Goulart \& Rosa, 2004; Horngren, Datar, \& Foster, 2004; Martins, 2010). Assim, as perdas anormais não fazem parte do dia a dia, pois não ocorrem usualmente; não são esperadas, planejadas ou desejadas e não 
ocorrem com regularidade, tornando praticamente impossível sua previsão. Em síntese, o conceito vigente é que perdas anormais não integram o custo dos bens e serviços produzidos, devendo ser apropriadas diretamente ao resultado, sem se incorporarem ao custo dos produtos vendidos.

Para a contabilização das perdas anormais durante o processo produtivo podese assim proceder: Despesas com Perdas Anormais na Produção (Resultado) e Estoque de Produtos em Elaboração (Ativo Circulante). Caso já se tenha concluído o período de apuração, as perdas anormais devem ser retiradas do custo e registradas nas despesas do período, isto é: Despesas com Perdas Anormais na Produção (Resultado) e Custo do Produto (Resultado).

Segundo Kumar (2012), o valor das perdas anormais pode ser calculado conforme a Equação 1:

$$
\text { Perda Anormal }=\frac{\text { Custo Total }}{\text { Produção Total-Unidades Perdidas }} x \text { Unidades Perdidas }
$$

Assim, se, por exemplo, o custo total de produção de 100 unidades de certo produto for $R \$ 10.000,00$, tem-se custo unitário de $R \$ 100,00$. Suponha-se que, devido a perdas anormais na etapa de corte, verificou-se que foram produzidas apenas 90 unidades. Nessa situação as perdas anormais:

$$
\text { Perda Anormal }=\frac{10.000,00}{(100-10)} \times 10=1.111,11
$$

Esse valor, por se tratar de perdas anormais, deve ser lançado diretamente no resultado do período. Ou seja, o valor das unidades perdidas devido a perdas anormais não deve ser incorporado aos custos das unidades finais, pois, aumentam enganosamente o seu custo total. 


\section{CONSEQUÊNCIAS FINANCEIRAS DA CONTABILIZAÇÃO INADEQUADA}

Na gestão estratégica de custos, as empresas partem do preço de mercado para determinar seus custos e não o contrário (Souza \& Clemente, 2011). Para que uma empresa alcance competitividade e se mantenha competitiva, não se admite a aplicação simples de mark-up sobre custos com pouco ou nenhum controle. O custo total de produção é obtido pela soma de todos os custos, fixos e variáveis, ou diretos e indiretos e, por consequência, chega-se ao custo unitário da produção. Assim, o processo deve ser capaz de gerar um produto cujo custo seja inferior ao preço praticado pelo mercado.

Quando a contabilização das perdas anormais é incorretamente atribuída à produção corrente, infla-se indevidamente o custo total de produção e, por consequência, o custo unitário. $O$ custo pode representar uma barreira à entrada em determinado mercado, caso uma empresa entrante deva incorrer em custos que não estão sendo desembolsados pelas empresas estabelecidas, impossibilitando a empresa entrante de obter suficiente lucratividade (Kupfer, 2013). Nessas condições, a prática automática de aplicação de mark-up sobre o custo unitário pode resultar em oferta não atrativa segundo a percepção dos consumidores.

Sweezy (1939), com sua curva de demanda quebrada, explica porque os preços são estáveis nos mercados oligopólios, como mostra a Figura 3.

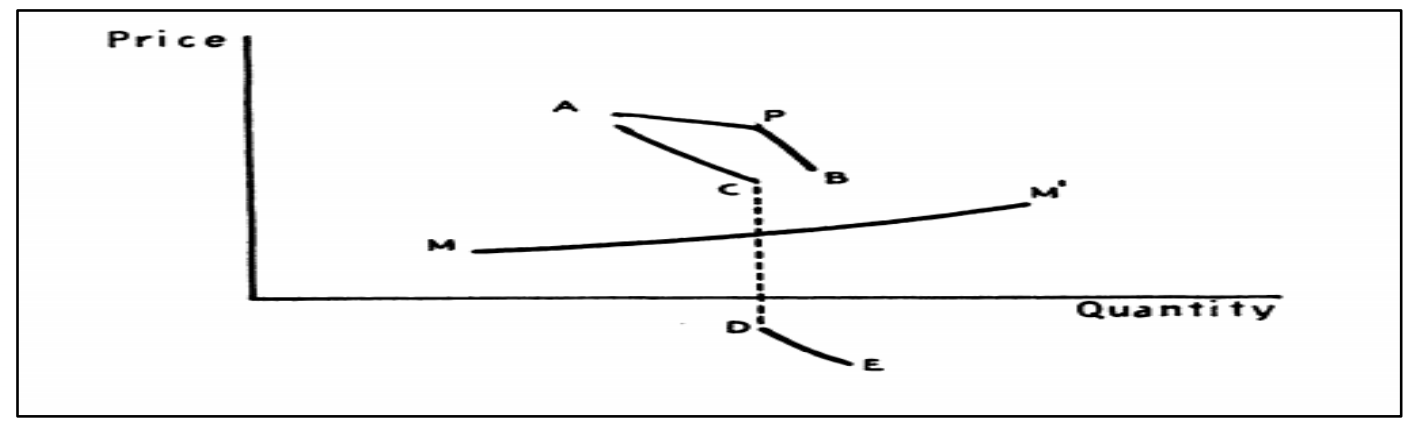

Figura 3: Curva de Demanda Quebrada

Fonte: Sweezy (1939). 
A Figura 3 mostra um ângulo na curva de demanda ao produtor oligopolista (APB) na condição de equilíbrio de mercado. Esse ângulo ou quebra da curva de demanda corresponde a uma descontinuidade na curva de receita marginal (ACDE). Então, do ponto de vista do ofertante oligopolista, não interessa aumentar o preço porque os concorrentes não o acompanhariam e ele arcaria com grandes reduções nas vendas e nas receitas. Ao mesmo tempo, ao concorrente oligopolista não interessa buscar aumento de vendas por meio de redução do preço, porque os concorrentes procurariam manter suas participações no mercado e o acompanhariam, resultando a manobra apenas em redução de receitas.

O aumento do preço de venda, especialmente em ambientes competitivos, pode representar redução significativa de vendas e de receitas. A redução nas vendas levará à redução nas quantidades produzidas e elevação do custo unitário, devido ao aumento do custo fixo unitário. Elevação do custo unitário significa nova elevação de preço via aplicação de mark-up, resultando em mais redução de vendas e conduzindo a crescentes reduções de Market-Share. Esse processo é conhecido como ciranda ou espiral da morte (Souza \& Clemente, 2011). Empresas inseridas em estruturas de mercado menos concorrenciais podem adotar a prática de incorporar perdas anormais aos custos e repassá-las via preço, mas isso obviamente dentro de certos limites.

A elevação dos custos, ocasionada pela diluição das perdas anormais aos produtos, acarreta informação enviesada nas demonstrações contábeis. De acordo com o CPC-16 valores anormais que não contribuem para trazer o estoque ao seu local e condição atual não devem ser contabilizados como custo e sim como despesas. Em síntese, informação enviesada nos relatórios contábeis, originada da contabilização inadequada de perdas anormais, apresenta consequências financeiras relevantes, cabendo destacar o elevado risco de perda de Market-Share e de embarque na denominada espiral da morte. 


\section{CONSEQUÊNCIAS GERENCIAIS DA CONTABILIZAÇÃO INADEQUADA}

As consequências gerenciais da informação distorcida, gerada pela contabilização incorreta de perdas anormais não são menos graves. Uma consequência óbvia advém do fato de a contabilização incorreta mascarar eventos que poderiam ser mitigados ou eliminados. Do ponto de vista gerencial, é importante ter presente que a ocorrência de perdas anormais possivelmente indica que não se conhecem bem todos os condicionantes do processo de produção e de logística. Daí a análise a ser criteriosamente realizada diz respeito à eventualidade, à aleatoriedade e à imprevisibilidade das perdas ocorridas. Afinal, se tais perdas estão completamente fora do alcance gerencial, efetivamente há pouco a fazer. A contabilização incorreta de perdas anormais de forma usual, sem que as correções necessárias e possíveis sejam efetivadas elimina ou posterga a melhoria de processos.

$\mathrm{Na}$ prática, as perdas anormais estariam sendo contabilizadas e tratadas como perdas normais. Se, por exemplo, tiverem ocorrido perdas anormais devido à deterioração de materiais indevidamente armazenados ou armazenados por prazo superior ao período de validade, ao incorporar esses valores aos custos de produção, a gestão não perceberá a necessidade das medidas corretivas adequadas ao caso. Ainda, se por exemplo, a preparação de equipamentos (setup) tiver demorado mais do que o planejado, tiver consumido mais materiais e mão de obra do que o planejado, tiver sido mais frequente do que o planejado etc (Fogliatto \& Fagundes, 2003), do ponto de vista gerencial é indispensável que haja o alerta relativo a perdas anormais e que todo o processo de setup passe por cuidadosa análise. Se no período de apuração se obteve um volume de unidades defeituosas superior ao previsto esses valores, se registrados como custo, ocultam o real valor empregado durante o processo produtivo. O simples registro desses gastos superiores aos planejados como custos de produção subtrai da gerência a oportunidade de analisá-los e tomar as medidas necessárias para que sejam mitigados ou eliminados.

Por fim, segundo Russo (2017), tem-se a possibilidade de que a prática 
contumaz de contabilizar inadequadamente perdas anormais como se fossem normais crie hábitos e até mesmo uma subcultura, configurando uma situação em que as mencionadas perdas anormais acabem se incorporando ao dia a dia da empresa, constituindo os denominados sticky costs ou custos pegajosos.

Em síntese, as implicações gerenciais acerca da contabilização incorreta de perdas anormais ao custo do produto representam falta de informações para aumentar ou reduzir a produção de determinado produto, desconhecimento da margem de contribuição unitária e exatidão dos custos de manutenção, aquisição e demais custos realizados na produção.

\section{GANHOS ANORMAIS, O CASO INVERSO}

Ganhos anormais ocorrem quando as perdas no processo de produção se situam aquém das perdas normais. Quando as perdas no processo de produção forem inferiores àquelas previstas, tidas como inerentes ao processo, é necessário reconhecer a ocorrência de ganhos anormais no período de apuração. Tais ganhos anormais deveriam merecer especial atenção gerencial porque representam prováveis oportunidades de melhorias permanentes do processo de produção.

$O$ desafio reside em analisar cuidadosamente as circunstâncias em que foi observado uma ou poucas vezes e incorporar definitivamente ao processo produtivo a redução de custo observada. Cabe verificar, por exemplo, se a ocorrência de ganho anormal está relacionada a alguma alteração no quadro de fornecedores, nos processos de controle de materiais, na concessão de incentivos e prêmios, na mudança de horários etc. e avaliar a possibilidade de ajustes visando otimizar todo o processo de produção.

A análise detalhada dos ganhos anormais é da maior importância para a gestão de custos porque pode significar a possibilidade de incorporá-los ao processo produtivo e de obter redução dos custos de produção de forma permanente. Assim, a utilização de materiais de novos fornecedores; alterações no fluxo de produção, incluindo fluxos 
de pessoas e fluxos e estocagem de materiais; alterações no setup de máquinas etc. podem dar origem casual ou intencionalmente experimentada para redução das perdas normais do processo de produção.

\section{ALGUNS EXEMPLOS DE CONTABILIZAÇÃO DE PERDAS}

Para ilustrar os reflexos da contabilização incorreta, podem ser considerados alguns exemplos, a saber: Produção de palmito em conserva; Unidade industrial de cerâmica; Colheita florestal de Pinus Serpes; Produção e transporte de trigo e Farinha de trigo e Perda de validade de componentes de ração.

\subsection{Produção de palmito em conserva}

O processo de produção de palmito em conserva é bastante simples, tal como apresentado na Figura 4. 


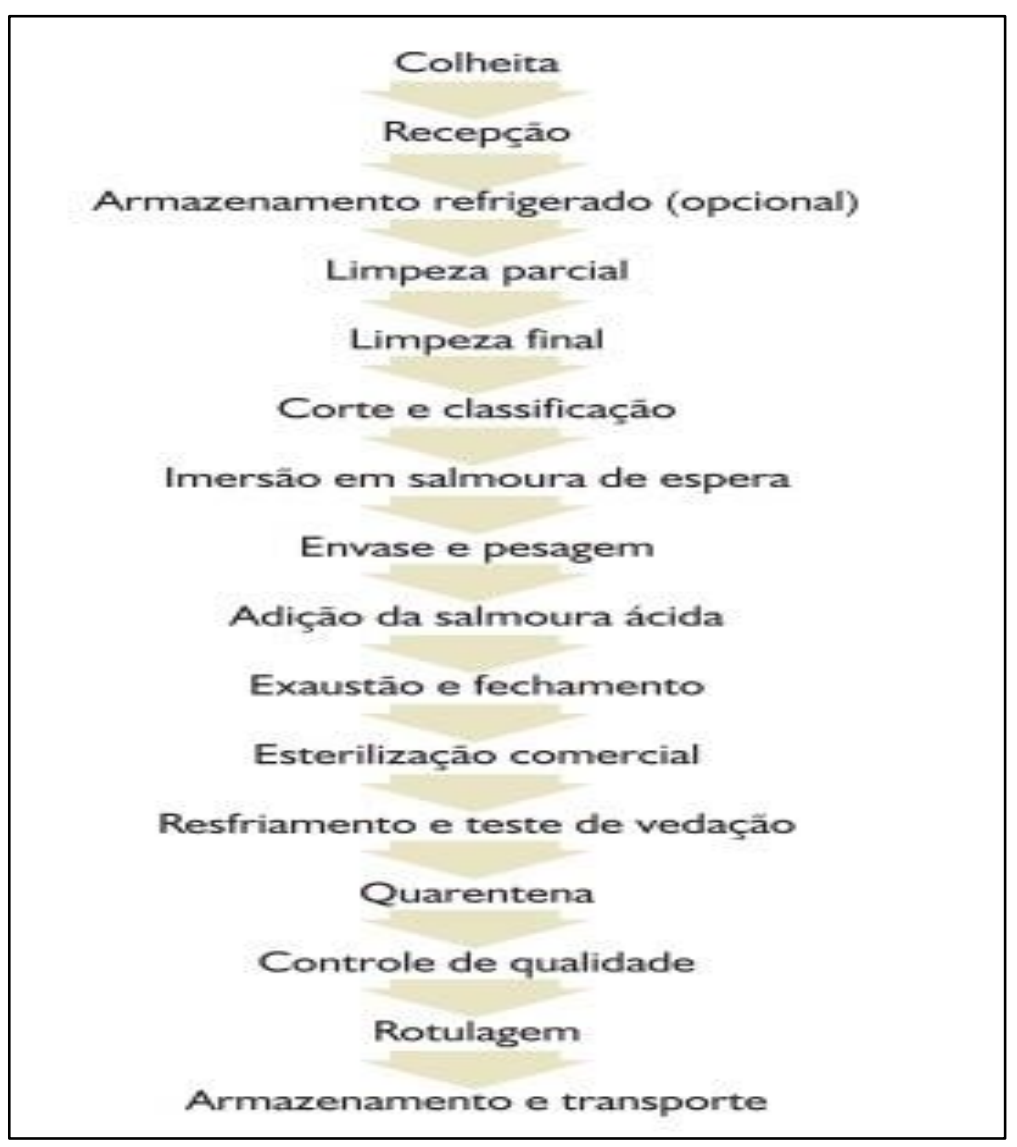

Figura 4: Etapas do processamento de palmito em conserva Fonte: Resende, Saggin Júnior, Silva e Flori (2009).

Dentre as etapas mostradas na Figura 4, o envase se caracteriza por apresentar cerca de $5 \%$ de perdas normais, porque quando os pedaços de palmito estão sendo arranjados dentro dos potes de vidro, ocorrem rupturas e deformações. Assim, mesmo sendo tomados todos os cuidados para não forçar a entrada dos toletes de palmito nos potes, ocorrem perdas normais de $5 \%$. Se durante certo período, por exemplo, as perdas no processo de envase alcançaram $7 \%$, deve-se reconhecer perdas anormais equivalentes a $2 \%$ da produção, levadas diretamente à apuração do resultado.

\subsection{Unidade industrial de cerâmica}

Bianchet et al. (2016) estudaram uma unidade industrial de cerâmica, com 23 funcionários, que produzia tijolos de barro cozido. A produção alcançava entre 300.000 
e 350.000 peças por mês, com revenda mensal de 250 mil unidades. Conforme relatam, a produção passa por sete etapas, começando pela mistura das matériasprimas (argila, serragem e pó de brita). Na sequência a mistura vai para as formas de moldagem. Daí é realizada a secagem natural, seguida da secagem em estufa. A etapa seguinte é o cozimento em forno a 780 graus Celsius. Quando o produto está pronto, é feita a classificação em tipo 1 (ótima qualidade) e tipo 2 (qualidade inferior). $O$ percentual médio de perdas no processo produtivo, principalmente na secagem e no cozimento, alcança $5 \%$ do total de produção. Os registros da empresa apontaram os níveis mostrados no Quadro 2.

\begin{tabular}{|lcccc|}
\hline & $\begin{array}{c}\text { Quebras } \\
\text { Normais }\end{array}$ & $\begin{array}{c}\text { Refugos } \\
\text { Normais }\end{array}$ & $\begin{array}{c}\text { Quebras } \\
\text { Anormais }\end{array}$ & $\begin{array}{c}\text { Refugos } \\
\text { Anormais }\end{array}$ \\
\hline Fevereiro & 4,58 & 1,82 & 0,09 & 0,05 \\
Março & 4,59 & 1,84 & 0,1 & 0,04 \\
\hline
\end{tabular}

Quadro 2: Quebras e refugos da unidade industrial de cerâmica em porcentagem Fonte: Bianchet et al. (2016).

Nesse caso, cabe à contabilidade registrar as perdas normais no custo e as anormais, diretamente no resultado do período.

\subsection{Perdas na colheita florestal de Pinus}

Serpe, Figueiredo Filho e Arce (2018) analisaram as perdas volumétricas relacionadas à colheita de Pinus Serpe. Do corte resultam subprodutos que compreendem: resíduos; toco conforme; serragem de derrubada; serragem de processamento; toco não conforme e quebra do fuste. As perdas anormais se referem ao toco não conforme e à quebra do fuste. A Tabela 1 apresenta os dados coletados pelos autores: 
Tabela 1

Percentual de volume comercial e perdas volumétricas na colheita florestal

\begin{tabular}{lcccc}
\hline Resultado do Processo & Classe & $\mathbf{m}^{\mathbf{3}} / \mathbf{h e c t a r e}$ & $\%$ & $\boldsymbol{\Sigma} \%$ \\
\hline \multirow{2}{*}{ Comercial } & Serraria 1 & 142,64 & 53,52 & \\
& Serraria 2 & 79,03 & 29,65 & \\
& Celulose & 13,07 & 4,9 & 88,08 \\
& & & & \\
& Resíduo & & & \\
& Toco conforme & 17,37 & 6,52 & \\
Perdas inerentes ao processo & Serragem de derrubada & 3,59 & 1,35 & \\
& Serragem de & 0,5 & 0,19 & \multirow{2}{*}{ processamento } \\
Perdas de colheita florestal & Toco não conforme & 0,84 & 0,32 & 8,37 \\
\hline Total & Quebra de fuste & 9,23 & 0,09 & \\
\hline
\end{tabular}

Nota. Fonte: Serpe, Figueiredo Filho, e Arce (2018).

No caso, as perdas volumétricas na colheita florestal totalizaram $11,92 \%$. "A perda econômica na atividade de colheita foi de $1,38 \%$ e representou $R \$ 330,85$ ha $^{-1}$. Considerando o volume retido no toco acima do padrão (acima de $0 \mathrm{~cm}$ ), a perda econômica foi de $R \$ 30,60$ ha $^{-1}$ e a perda por quebra de fuste foi de $R \$ 300,25 \mathrm{ha}^{-1}$ (Serpe; Figueiredo Filho \& Arce, 2018). Como nos outros casos, as perdas normais devem integrar o custo do produto, enquanto as anormais devem ser contabilizadas como despesa, diretamente no resultado.

\subsection{Perdas na produção e no transporte de trigo}

Rocha, Péra, Caixeta Filho e Bartholomeu (2017) levantaram o fluxo de movimentação do trigo, conforme Figura 5. 


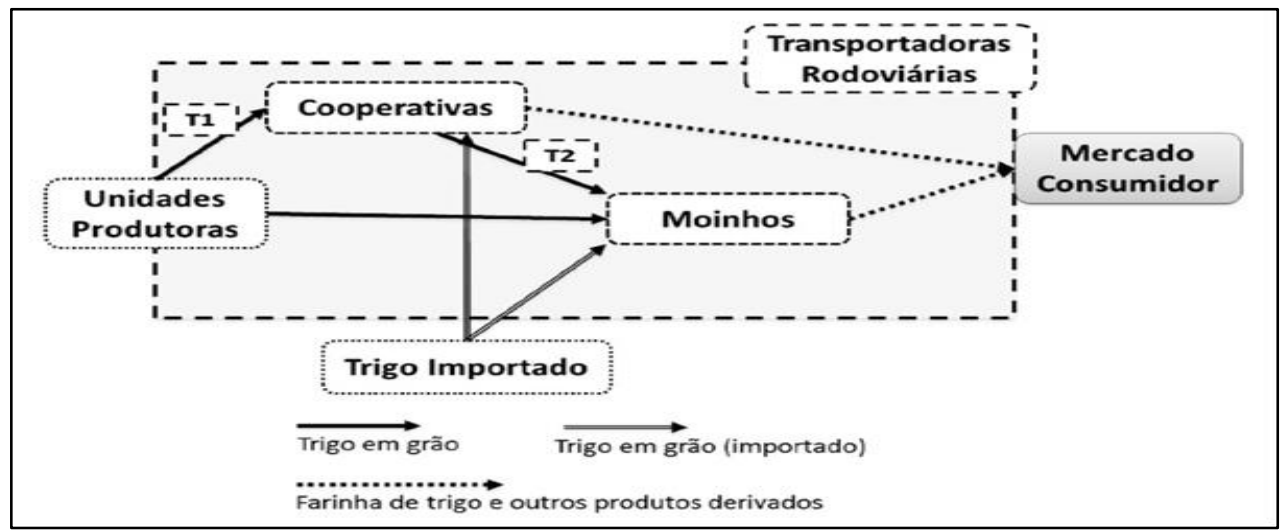

Figura 5: Fluxos de movimentação do trigo

Fonte: Rocha (et al., 2017).

Conforme a Figura 5, o trigo sai das unidades produtoras agrícolas e chega às cooperativas (T1) e diretamente aos moinhos. Das cooperativas segue para os moinhos (T2). Nos moinhos, o trigo é processado e transformado em farinha e farelo de trigo. Os autores estimaram as perdas nesse fluxo conforme a Figura 6.

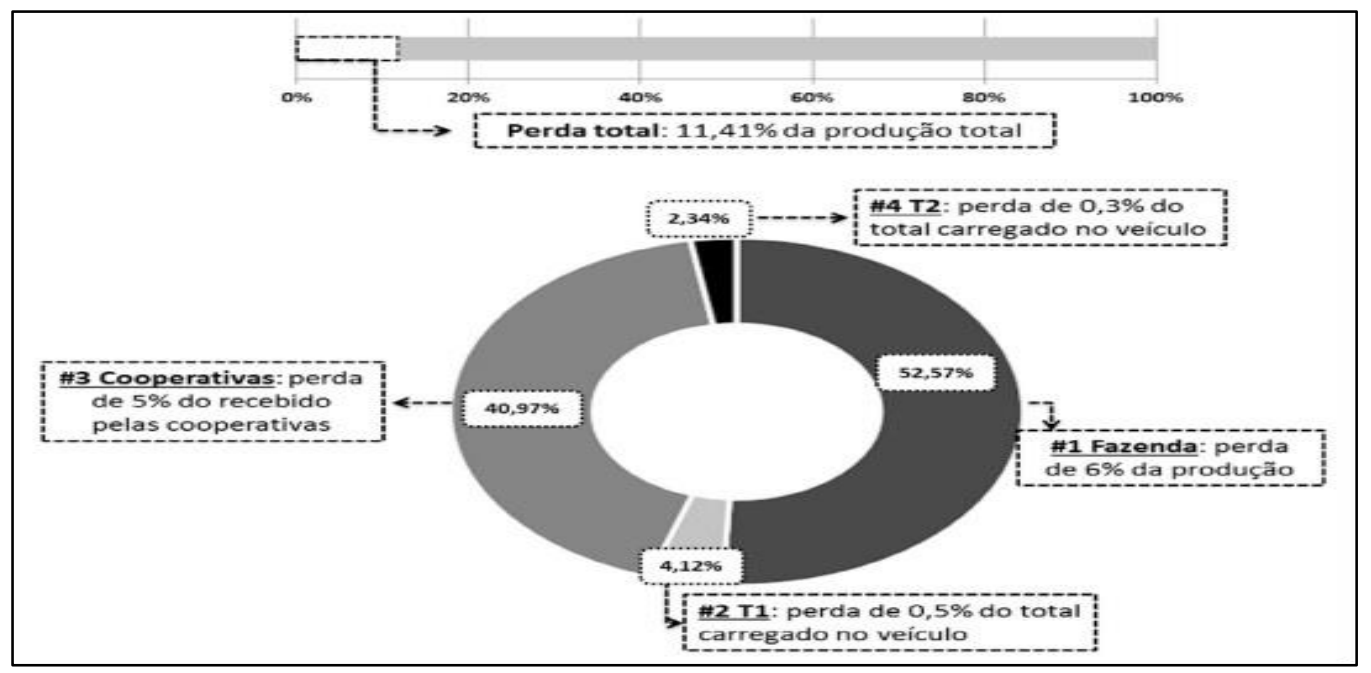

Figura 6: Estimativa de perdas na cadeia logística do trigo Fonte: Rocha et al.(2017).

As perdas totais na cadeia produtiva do trigo correspondem a $11,41 \%$ do trigo em grão produzido. Destacam-se nesse contexto, as perdas na colheita e na armazenagem junto às cooperativas (que respondem por $93,55 \%$ das perdas totais). As 
operações de transporte (T1 e T2) representam 6,45\% das perdas totais (Rocha et al., 2017). Ao longo de toda a cadeia, as perdas normais, consideradas inerentes ao processo, devem ser reconhecidas como custo, enquanto todas as perdas anormais que eventualmente ocorram devem ser apropriadas como despesas, gravando diretamente o resultado das empresas envolvidas.

\subsection{Farinha de trigo deteriorada por umidade}

Certo moinho produz farinha e farelo de trigo. No último mês houve exposição acidental de 30 toneladas de farinha a umidade no sistema logístico de distribuição, tornando-a imprópria para consumo humano e animal. Nesse caso, a produção danificada deve ser vendida para produção de cola, com deságio de cerca de $R \$ 60,00$ por tonelada. Essa perda de valor da farinha exposta acidentalmente à umidade, igual a $R \$ 1.800,00$, deve ser contabilizada diretamente no resultado do período, enquanto 0 custo de produção das 30 toneladas deve integrar o custo de produção do mês, bem como elas devem ser consideradas produção do período.

\subsection{Perda de validade de componentes de ração}

Em certa fábrica de ração, alguns componentes, por falha no controle de estoque, perderam a validade, devendo ser descartados. A perda correspondente deve ser reconhecida diretamente no resultado, não afetando os custos das rações produzidas no período.

Essas ilustrações mostram como as perdas normais e anormais que podem ocorrer no processo de produção deveriam ser corretamente contabilizadas para que a informação contábil seja adequada à tomada de decisões. Quando as perdas anormais são equivocadamente reconhecidas como custo e não como despesa do período de apuração, a gerência recebe sinalização enganosa, expondo a empresa a riscos desnecessários, como visto antes. 


\section{CONCLUSÃO}

Procurou-se com este artigo mostrar a inconveniência da prática incorreta, mas usual de contabilizar perdas anormais como custo de produção. Essa prática, embora comum, é antiquada porque não valoriza a contabilidade de custos como fonte de informação relevante para a gestão, especialmente para a gestão estratégica. Constata-se que a gestão estratégica requer informação completa e tempestiva a respeito dos custos da estrutura implantada e do modus operandi atual, bem como de suas alternativas.

Ao contrário do que ocorre com perdas normais (de processo), as perdas anormais podem ocorrer antes, durante ou após o processo de produção. O esquema do Quadro 3 mostra a contabilização correta em cada caso.

\begin{tabular}{|c|c|c|}
\hline \multicolumn{3}{|c|}{ PROCESSO PRODUTIVO } \\
\hline ANTES & DURANTE & DEPOIS \\
\hline $\begin{array}{c}\mathrm{D} \text { - Perdas anormais de } \\
\text { matéria prima (Resultado) } \\
\mathrm{C} \text { - Estoque de matéria prima } \\
\text { (Ativo circulante) }\end{array}$ & $\begin{array}{c}\text { D - Perdas anormais na } \\
\text { Produção (Resultado) } \\
\mathrm{C}-(-) \text { Perdas anormais na } \\
\text { produção (Custo de produção) }\end{array}$ & $\begin{array}{c}\text { D - Perdas anormais (Resultado) } \\
\text { C - Estoque de Produtos acabados } \\
\text { (Ativo Circulante) }\end{array}$ \\
\hline $\begin{array}{c}\text { Baixa no estoque do material } \\
\text { com contrapartida numa conta } \\
\text { de resultado. }\end{array}$ & $\begin{array}{l}\text { Vão diretamente para o } \\
\text { resultado, sem se } \\
\text { incorporarem aos produtos. }\end{array}$ & $\begin{array}{l}\text { Baixa no estoque de produtos } \\
\text { acabados com contrapartida numa } \\
\text { conta de resultado }\end{array}$ \\
\hline
\end{tabular}

Quadro 3. Contabilização de perdas normais e anormais Fonte: Autores (2019).

Do ponto de vista financeiro, a contabilização inadequada de perdas anormais induz à prática de repasse dessas perdas via Mark-up. A perda de vendas e de participação no mercado podem representar o início de um processo de difícil reversão em que a empresa encontrará dificuldades crescentes para se manter competitiva.

Do ponto de vista gerencial, as implicações também são danosas, seja porque a contabilização inadequada das perdas anormais esconde a situação real e retira a possibilidade de ações corretivas, seja porque, deixando de atuar nas causas das 
perdas anormais, elas podem se tornar frequentes e, finalmente, passarem a ser consideradas normais. Em particular, é valioso reconhecer que quando as perdas anormais são corretamente contabilizadas como despesas do período, a empresa não corre o risco de tentar passar aos seus clientes valores que não integram o custo de produção, via Mark-up. Essa tentativa se configura altamente arriscada porque proporciona aos competidores a possibilidade de aumentarem suas vendas às custas da empresa que majorou seus preços. Além disso, e não menos importante, a contabilização correta abre a possibilidade de ações corretivas para que se evitem perdas anormais.

Apesar das implicações danosas da contabilização incorreta de perdas anormais, é necessário reconhecer que não há fórmula predefinida para diferenciá-las das perdas normais de processo. O conhecimento do processo e a análise das circunstâncias e do contexto em que as perdas ocorreram servirão de base para o julgamento e a decisão sobre como devem ser consideradas. No limite, a diferenciação será resultado de uma opção gerencial, o que torna evidente a importância de conhecer profundamente o processo de produção. De qualquer forma, nenhuma decisão a respeito da contabilização de perdas deveria ser realizada sem a participação dos que estão diretamente envolvidos no processo de produção.

Quanto aos ganhos anormais, é preciso que as suas origens sejam detalhadamente analisadas com vistas a torná-los permanentes e, assim, se refletirem em redução do custo de produção. A ocorrência de ganhos anormais é no mínimo um alerta quanto à possibilidade de redução de custo. É indispensável que a ocorrência de ganhos anormais seja totalmente explicada para que, conhecendo completamente suas causas, sejam desenvolvidas mudanças e ajustes para incorporá-los ao processo produtivo.

Por fim, cabe ressaltar que o custo de produção é uma informação contábil fundamental à gestão de toda empresa porque essa deve sobreviver e crescer e, para tanto, há de ser lucrativa. Quando tal informação não se apresenta com qualidade, em particular quando não é tempestiva e fidedigna, as decisões gerenciais, tanto 
estratégicas quanto operacionais, provavelmente não estarão na direção certa ou restarão defasadas.

Cabe salientar que a presente pesquisa possui limitações que envolvem os estudos que foram considerados para análise. Como sugestão para estudos futuros, segure-se analisar outras pesquisas que tiveram como foco a temática estudada, bem como, verificar de forma empírica as implicações acima mencionadas.

\section{REFERÊNCIAS}

Amaral, J. V., \& Guerreiro, R. (2018). Reflexões sobre o estabelecimento de preços a partir dos custos e dos preços das ofertas concorrentes: a lacuna pode não ser tão profunda. Revista de Contabilidade e Organizações, 12.

Amaral, J. V., \& Guerreiro, R. (2018). Preços estabelecidos com base nos custos: por quê?. In Anais do Congresso Brasileiro de Custos-ABC.

Banterle, A., Carraresi, L., \& Cavaliere, A. (2011). What is the role of marketing capability to be a price maker? An empirical analysis in Italian food SMEs. Economia e Diritto Agroalimentare, 16(2), 245.

Bhargava, R. (2018) Normal Loss, Abnormal Loss and Abnormal Gain. Recuperado de: <http://www.yourarticlelibrary.com/accounting/normal-loss-abnormal-loss-andabnormal-gain/76703>. Acesso em: 23/jul./2020.

Bianchet, T. D. S. A., Zanin, A., de Camargo, T. F., \& Diel, F. J. (2016). Mensuração do valor das perdas normais e anormais no processo produtivo de uma indústria cerâmica. In Anais do Congresso Brasileiro de Custos-ABC.

Bornia, A. C. (1995). A utilização do método da unidade de esforço de produção na quantificação das perdas internas da empresa. In Anais do Congresso Brasileiro de Custos-ABC.

Bornia, A. C. (2010). Análise gerencial de custos: aplicação em empresas modernas. São Paulo: Atlas.

Brasil, Receita Federal. (1999). Regulamento do imposto de renda RIR/99. Regulamenta a tributação, fiscalização, arrecadação e administração do Imposto sobre a Renda e Proventos de Qualquer Natureza. 
Brasil. Constituição (1977). Decreto-lei no 1.598, de 1977 Altera a legislação do imposto sobre a renda. Brasília.

Chandler, A. D. (1977). The Visible Hand: The Managerial Revolution in American Business Harvard University Press Cambridge.

Cogan, S. (2013). Custos e formação de preços: análise e prática. Editora Atlas.

Comitê, De Pronunciamentos Contábeis-CPC; BÁSICO, Pronunciamento Conceitual. CPC-16: Estoques. Brasília, maio, 2009.

Cooper, R., \& Kaplan, R. S. (1988). Measure costs right: make the right decisions. Harvard business review, 66(5), 96-103.

Costa, R. P. D., Ferreira, H. A. S., \& Saraiva Júnior, A. F. (2013). Preços, orçamentos e custos industriais: fundamentos da gestão de custos e de preços industriais; inclui o sistema de apoio à decisão POC.

Estrela, G. Q., da Cruz, C. L. R., \& Severiano Filho, C. (1999). Identificação E Mensuração Das Perdas Internas Do Processo Produtivo De Uma Indústria De Curtume Utilizando O Método ABC. In Anais do Congresso Brasileiro de Custos$A B C$.

Fogliatto, F. S., \& Fagundes, P. R. M. (2003). Troca rápida de ferramentas: proposta metodológica e estudo de caso. Gestão \& Produção, 10(2), 163-181.

Goulart, M., \& Rosa, L. (2004). O Tratamento Contábil Das Perdas Ocorridas No Processo Produtivo Como Elemento De Qualidade. In Anais do Congresso Brasileiro de Custos-ABC.

Horngren, C.T., Datar, S. M., \& Foster, G. (2004). Contabilidade de custos: uma abordagem gerencial. V. 1. Tradução por Robert Brian Taylor e revisão técnica por Arthur Ridolfo Neto, Antonieta E. Magalhães Oliveira, Fábio Gallo Garcia.

Johnson, H. T. \& Kaplan, R. S. (1993). Contabilidade gerencial: a restauração da relevância da contabilidade nas empresas.

Keynes, J.M. (1965). Teoria Geral do emprego, do Juro e da Moeda. Fundo de Cultura.

Kupfer, D. (2013). Barreiras estruturais à entrada. In: Kupfer, D; Hasenclever, Lia. Economia industrial: fundamentos teóricos e práticas no Brasil. Elsevier.

Kumar, V. (2012). Treatment of Normal and Abnormal Loss in Process Costing. 
Recuperado de: <http://www.svtuition.org/2012/10/treatment-of-normal-andabnormal-loss_29.html>. Acesso em: 25/jul./2020.

Kotler, P. (1999) Marketing Management. Millennium Ed New Jersey: Prentice Hall.

Lopes, L. F. D., de Brum, D. V., \& de Gregori, R. (2008). As perdas do processo produtivo na fabricação de massas alimentícias. In Anais do Congresso Brasileiro de Custos-ABC.

Maher, M. (2001). Contabilidade de custos: criando valor para a administração. Atlas.

Martins, E. (2010) Contabilidade de custos. São Paulo: Atlas.

Nagle, T. T., \& Holden, R. K. (2003) Estratégias e Táticas de preços: um guia para decisões lucrativas. São Paulo: Prentice Hall.

Possas, S. (2006). Concorrência e inovação. In: Pelaez, V. \& Szmrecsanyi, T. Economia da inovação tecnológica. Ed. Hucitec.

Resende, J. M., Saggin Júnior, O. J., Silva, E. D., \& Flori, J. E. (2009). Palmito de pupunha in natura e em conserva. Brasília: Embrapa Informação Tecnológica.

Rocha, F. V. D., Péra, T. G., Caixeta Filho, J. V., \& Bartholomeu, D. B. (2017). Mensuração de perdas de pós-colheita na cadeia de suprimento de moageiras do trigo no Rio Grande do Sul. Teoria e Evidência Econômica, 23(48), 39-62.

Russo, C. P. (2017). Sticky costs: uma análise crítica da teoria e metodologia utilizada em trabalhos publicados sobre o comportamento de custos (Doctoral dissertation) Universidade de São Paulo, USP, São Paulo.

Santos, J. L. D., Schmidt, P., Pinheiro, P. R., \& Nunes, M. S. (2015). Manual de contabilidade de custos. São Paulo: Atlas, 260.

Serpe, E. L., Figueiredo Filho, A., \& Arce, J. E. (2018). Perdas volumétricas relativas à colheita florestal e seus reflexos econômicos. BIOFIX Scientific Journal, 3(1), 172176.

Shingo, S. (1996). Sistema Toyota de produção: do ponto-de-vista de engenharia de produção. Porto Alegre: Bookmann.

Stackelberg, H. (1952). The theory of Market economy. Nova York: Oxford University Press. 
Souza, A., \& Clemente, A. (2007). Gestão de Custos: aplicações operacionais e estratégicas. São Paulo: Atlas.

Sweezy, P. M. (1939). Demand under conditions of oligopoly. Journal of Political Economy, 47(4), 568-573.

Smith, A. (1996). Os Economistas: Adam Smitch - A Riqueza das Nações. São Paulo: Nova Cultural.

Taylor, F.W. (1989). Princípios de Administração Científica. São Paulo: Atlas.

Data de Submissão: 22/12/2020

Data de Aceite: 10/08/2021 